\title{
Flow cytometry enables dynamic tracking of algal stress response: A case study using carotenogenesis in Dunaliella salina
}

\author{
Melanie Fachet ${ }^{a}$, Dana Hermsdorfa, Liisa Rihko-Struckmann ${ }^{\mathrm{a}, \star}$, Kai Sundmacher ${ }^{\mathrm{a}, \mathrm{b}}$ \\ ${ }^{a}$ Max Planck Institute for Dynamics of Complex Technical Systems, Process Systems Engineering, \\ Sandtorstr. 1, 39106 Magdeburg, Germany. \\ ${ }^{b}$ Otto von Guericke University Magdeburg, Process Systems Engineering, \\ Universitätsplatz 2, 39106 Magdeburg, Germany.
}

\begin{abstract}
The cultivation under adverse growth conditions is a commonly used strategy to trigger carotenoid accumulation in microalgae. In order to characterize important factors affecting the biotechnological productivity of a microalgal species systematic and accurate analysis of cellular properties and the physiological response to abiotic stress is required. Therefore, we have investigated the influence of various stress types on a broad spectrum of cellular properties in a dynamic manner. Cellular properties were monitored in stained samples for cell vitality and neutral lipid fluorescence together with intrinsic parameters. The results revealed that nitrogen limitation and oversaturating light induced distinct adaptational responses in the cells. In the presence of nitrogen stress, the homogeneous population distribution splitted into two heterogeneous sub-populations for the cell vitality and neutral lipid fluorescence. Furthermore, we have demonstrated that flow cytometry is able to rapidly detect changes in the cell population upon exposure to abiotic stress. On the basis of
\end{abstract}

\footnotetext{
${ }^{*}$ Corresponding author. E-mail address: rihko@mpi-magdeburg.mpg.de, Tel. +49 3916110 318, Fax: +493916110353.
}

Preprint submitted to Algal Research

November 13, 2015 
this finding, it is possible to determine optimal harvesting time points based on the product content and culture vitality. This enables new perspectives for flow cytometry in the analysis of the metabolic stress response for robust production strategies of microalgal metabolites.

Keywords:

Dunaliella salina, $\beta$-carotene, flow cytometry, cellular properties

\section{Introduction}

2

A large variety of commercially interesting microalgal products, such as primary and secondary metabolites are nowadays produced in biotechnological processes (Koller et al., 2014). The recent advances in new analytical techniques for algal cell biology, which require only a minimal sample amount and enable fast preparation allow for a more detailed and comprehensive bioprocess characterization (Wagner et al., 2010; Havlik et al., 2013; Biller and Ross, 2014). A profound and extensive understanding of the process enables the determination of critical process parameters such as an optimal harvesting time point. Among other factors, the reactor setup, the nutrient composition in the growth medium and the environmental conditions, especially the light intensity, play the most important role to obtain a desired product content and quality. Unfavorable environmental conditions, such as high light intensity, high salinity or nutrient depletion can lead to metabolic imbalances and cause a complex adaptive physiological stress response (Mulders et al., 2014b). In the course of their evolution, microalgae have developed efficient strategies to tolerate and adapt to various types of abiotic stress. The sensing of abiotic stress induces a signaling cascade in the cell that leads to the activation of stress-responsive genes, the up-regulation of antioxidant pathways and the accumulation of secondary metabolites resulting in an adjustment of the cellular state to the new physiological 
conditions (Pérez-Clemente et al., 2013). Since most commercially relevant high value products, such as triacylglycerides (TAGs) and carotenoids, are accumulated under abiotic stress, changes in the environmental stimuli can result in cell death and thus negatively affect process robustness and the applicability of control strategies (Jiménez et al., 2009). Therefore, a detailed characterization of these phenomena is necessary as a basis for robust process design of large scale cultivation systems.

In the presence of abiotic stress, the halotolerant green microalga D. salina is rich in $\beta$-carotene. Even though, the overaccumulation of $\beta$-carotene in D. salina has been investigated extensively, only little is known about the cellular response and the regulatory mechanisms involved in the underlying adaptational stress response (BenAmotz et al., 1982; Lamers et al., 2010). Exposure of the cells to high irradiance is the main trigger that induces photooxidative processes, which initiate the enrichment of photoprotective carotenoid pigments. The underlying photoprotective mechanisms of $\beta$-carotene are the prevention of oxidative damage by scavenging reactive oxygen species and the absorption of UV light, avoiding direct damage of cellular targets (Mulders et al., 2014b). The overaccumulated $\beta$-carotene, which is mainly composed of the two isomers, 9-cis and all-trans, is stored in TAG-containing lipid globules in the interthylakoid space of the chloroplast (Ben-Amotz et al., 1982). Results from previous studies pointed out that TAG synthesis and $\beta$-carotene formation are interlinked, creating a metabolic sink avoiding end-product inhibition in the carotene biosynthesis pathway (Rabbani et al., 1998; Mendoza et al., 1999). This coincides with the fact, that massive carotene accumulation is enhanced with increasing abiotic stress, e.g. nutrient deprivation.

Flow cytometry is a widely used method in marine ecosystems research to investigate the structure and distribution of phytoplankton in natural seawater samples (Olson et al., 1985). The recent interest in oleaginous microalgae for the production of 
biofuels and edible oils has extended the application of flow cytometry to the staining microalgal lipid bodies with lipophilic dyes, such as Nile Red and BODIPY (Chen et al., 2009; da Silva et al., 2009; Brennan et al., 2012). In addition, flow cytometry provides information about population heterogeneity and can therefore be used for fluorescence-activated cell sorting (FACS) to separate cells overproducing a target compound (Bougaran et al., 2012; Xie et al., 2014). Moreover, flow cytometry also supports the analysis of various morphological and biochemical features referring to physiological state of the cell (Mendoza Guzmán et al., 2012; de Winter et al., 2013). Depending on the environmental conditions, the cell cycle stage or the age of a cell, intrinsic light scattering and fluorescence emission properties of the biomass will change. These changes in the cellular properties (e.g. cell size, granularity, pigmentation, vitality) will have a large impact on the process performance and flow cytometry has therefore the potential to contribute to the rapid development of feasible bioprocesses. Although the large scale production of natural $\beta$-carotene in D. salina is of high industrial relevance, a systematic and detailed analysis of cellular features corresponding to its physiological state during storage molecule accumulation under abiotic stress conditions has not been analyzed in detail.

The goal of the present work is to systematically explore the influence of abiotic stress on important bioprocess parameters, e.g. growth parameters, metabolic stress indicators, morphological properties and productivity in batch cultures of D. salina in a fully controlled flat-plate bioreactor setup.

\section{Materials and Methods}

\subsection{Strain, pre-cultivation and batch fermentations}

The D. salina strain (CCAP 19/18) was obtained in 2011 from the Culture Collection of Algae and Protozoa (Windermere, United Kingdom). The growth of the 
stock culture was performed in $500 \mathrm{~mL}$ shaking flasks containing $150 \mathrm{~mL}$ of the growth medium previously described by Lamers et al. (2010) on a rotary shaking incubator (Multitron, Infors AG, Switzerland) in air enriched with $3.5 \% \mathrm{CO}_{2}$, at $26^{\circ} \mathrm{C}, 100 \mathrm{rpm}$, with a light intensity of $30 \mu \mathrm{mol}$ photons $\mathrm{m}^{-2} \mathrm{~s}^{-1}$ and alternating day/night cycles $(16 \mathrm{~h} / 8 \mathrm{~h})$. The growth medium was composed of $1.50 \mathrm{M} \mathrm{NaCl}, 37.75 \mathrm{mM} \mathrm{KNO}_{3}$, $22.50 \mathrm{mM} \mathrm{Na}_{2} \mathrm{SO}_{4}, 4.87 \mathrm{mM} \mathrm{K}_{2} \mathrm{SO}_{4}, 1.00 \mathrm{mM} \mathrm{NaH}_{2} \mathrm{PO}_{4}, 0.37 \mathrm{mM} \mathrm{MgCl} 2,19.35 \mathrm{mM}$ $\mathrm{Na}_{2}$ EDTA, $18.9 \mathrm{mM} \mathrm{CaCl}_{2}, 11.25 \mathrm{mM} \mathrm{NaFe}$ EDTA, $1.89 \mathrm{mM} \mathrm{MnCl}_{2}, 1.48 \mathrm{mM} \mathrm{ZnSO}_{4}$, $0.67 \mathrm{mM} \mathrm{CuSO}_{4}, 10.95 \mathrm{nM} \mathrm{Na} 2 \mathrm{MoO}_{4}$, and $9.95 \mathrm{nM} \mathrm{CoCl}$.

Batch fermentations were performed in a flat-plate photobioreactor with $1 \mathrm{~L}$ cultivation volume and a thickness of $5 \mathrm{~cm}$ (FMT 150, Photon Systems Instruments, Czech Republic) continuously illuminated with white and red LEDs. The reactor was aerated with a gas mixture of $97 \%$ air and $3 \% \mathrm{CO}_{2}$ at a flow rate of $500 \mathrm{~mL} \mathrm{~min}{ }^{-1}$ controlled by mass flow controllers. A pH was adjusted to 7.5 by automated addition of $1 \mathrm{M} \mathrm{HCl}$ and $1 \mathrm{M} \mathrm{KOH}$. and the temperature was maintained at $24^{\circ} \mathrm{C}$ using peltier cooling. For inoculation, a stock culture grown under nitrogen-replete conditions was diluted to approximately $1 \times 10^{6}$ cells $\mathrm{mL}^{-1}$ with the appropriate medium. The transmitted light intensity was calculated by averaging the light intensity on the backside of the reactor measured at 4 different positions on its surface using a light sensor (ULM-500, Walz, Germany).

\subsection{Flow cytometric analysis}

All samples were diluted with cultivation medium to a cell density of approximately $1 \times 10^{6}$ cells $\mathrm{mL}^{-1}$ prior to the analysis. The cell density was monitored in diluted samples using volumetric counting of $200 \mu \mathrm{L}$ cell suspension. Intrinsic cellular properties, such as cell integrity and granularity were monitored in unstained cell samples using the light scattering properties of the biomass in the forward (FSC) and 
side scatter (SSC) channel. Cell vitality and lipid fluorescence were determined by staining with the corresponding dyes.

\subsubsection{Cell vitality staining}

The vitality of the cell culture was assessed using fluorescein diacetate (FDA). Esterases of metabolically active cells cleave the non-fluorescent probe into the green fluorescent compound fluorescein. A FDA stock solution $\left(2 \mathrm{mg} \mathrm{mL}^{-1}\right)$ was prepared in acetone. The staining was performed by adding $20 \mu \mathrm{L}$ of the FDA stock solution to $1 \mathrm{~mL}$ of cell suspension leading to a final concentration of $40 \mu \mathrm{g} \mathrm{mL}-1$ according to Hejazi et al. (2004).

\subsubsection{Lipid staining}

The lipophilic fluorescent dye Nile Red was used to estimate the neutral lipid content in D. salina. For this purpose, a stock solution of $1 \mathrm{mg} \mathrm{mL}^{-1}$ was prepared in dimethyl sulfoxide (DMSO). The cell suspension was treated with $25 \%$ DMSO and stained with a final concentration of $0.5 \mu \mathrm{g} \mathrm{mL}-1$ Nile Red and incubated for 15 minutes in the dark according to Chen et al. (2009) and Govender et al. (2012). All stained cell suspensions were immediately analyzed after dye incubation.

\subsubsection{Instrument settings, data acquisition and analysis}

The analysis of the above mentioned cellular properties was carried out in a flow cytometer (CyFlow Space, Sysmex-Partec, Germany) equipped with a blue argon solid state $(488 \mathrm{~nm})$ excitation laser. The signal intensities were calculated from the geometric mean values of the histograms and were displayed as arbitrary units (AU) per particle for the FSC and SSC signal or as relative fluorescent units (RFU) per particle for the different fluorescence emission channels FL1 - FL3 (see Table S1 for emission ranges). The sample flow rate was adjusted to $1 \mu \mathrm{L} \mathrm{s}^{-1}$, which corresponds 
to approximately 1,000 particles/s measured in a degassed $1.5 \mathrm{M} \mathrm{NaCl}$ solution as sheath fluid. Discrimination between the cellular signal and the background signal was performed by applying a gate on the red chlorophyll fluorescence emission signal (FL3) corresponding to the cellular signal. The algal cell populations inside the gate range were the dominant type of event detected (Fig. 1a). Data acquisition, gating and analysis were performed with FloMax software (Version 2.70).

\subsubsection{Fluorescence microscopy}

The flow cytometric measurements were validated using a light and epifluorescence microscope (Axio Imager A1, Carl Zeiss, Germany) equipped with a digital camera system. For comparison of the staining efficiency of the neutral lipids, staining with Nile Red was compared with BODIPY 505/515 according to the staining conditions $\left(0.067 \mu \mathrm{g} \mathrm{mL}^{-1}\right.$ final dye concentration and 5 minutes staining time) proposed by Govender et al. (2012).

\subsection{Pulse amplitude modulation (PAM) fluorometry}

The maximum photochemical quantum yield of PSII $\Phi_{\text {II }}$ was analyzed using the Dual-PAM 100 fluorometer (Walz, Germany). For this propose, $1.5 \mathrm{~mL}$ culture suspension adjusted to $5 \cdot 10^{6}$ cells $\mathrm{mL}^{-1}$ were dark adapted in a glass cuvette for $10 \mathrm{~min}$ at $26^{\circ} \mathrm{C}$. Afterwards, the minimal fluorescence level $\left(F_{0}\right)$ and maximal fluorescence level $\left(F_{\mathrm{m}}\right)$ induced by a saturating actinic light pulse $(635 \mathrm{~nm}, 2000 \mu \mathrm{mol}$ photons $\left.\mathrm{m}^{-2} \mathrm{~s}^{-1}, 0.5 \mathrm{~s}\right)$ were determined with a measuring radiation of $5 \mu \mathrm{mol} \mathrm{m} \mathrm{m}^{-2} \mathrm{~s}^{-1}$. The maximal photochemical quantum yield of PSII was calculated according to the following equation:

$$
\Phi_{\mathrm{II}}=\frac{F_{\mathrm{m}}-F_{0}}{F_{\mathrm{m}}}
$$




\subsection{Pigment extraction}

Samples of the cell suspension were centrifuged for 30 minutes at $1,000 \mathrm{~g}$. The supernatant was discarded and the cell pellet was washed with $1.5 \mathrm{M}$ ammonium formate. The sample volume was adapted to result in a biomass dry weight of approximately $3 \mathrm{mg}$. The pellet was freeze-dried and stored at $-20^{\circ} \mathrm{C}$ until extraction.

The extraction of the microalgal pigments was performed according to the method proposed by Lamers et al. (2010).

\subsection{Analysis of pigment composition}

The content of $\beta$-carotene, chlorophyll $a$ and $b$ in the biomass was quantified by High Performance Liquid Chromatography (HPLC) (Agilent 1100, Agilent Technology, USA), using a Reversed-Phase C18 column (Zorbax Eclipse Plus, $1.8 \mu \mathrm{m}$ pore size, $100 \mathrm{~mm} \times 2.1 \mathrm{~mm})$. An injection volume of $2 \mu \mathrm{L}$ was used for analysis. The elution was performed by a linear gradient from $100 \%$ A (84\% acetonitrile, $2 \%$ methanol, $14 \%$ Tris buffer $(0.1 \mathrm{M}, \mathrm{pH} 8.0))$ to $10 \% \mathrm{~A}$ and $90 \% \mathrm{~B}$ (68\% methanol, $32 \%$ ethyl acetate) for 2 minutes followed by elution with $100 \%$ B for 3 minutes at a flow rate of $0.5 \mathrm{~mL} \mathrm{~min} \mathrm{~m}^{-1}$ (Polle et al., 2001). Detection of the pigments was performed with a diode array detector (DAD) and a fluorescence detector (FLD) in a range from $400-800 \mathrm{~nm}$. The pigments were identified by comparing retention time and spectral properties with commercial pigment standards (Sigma Aldrich, USA). The pigment content in the biomass was quantified by constructing a calibration curve with the respective standard.

\subsubsection{Calculation of biomass and $\beta$-carotene yield on absorbed light}

For the evaluation of the process performance, the biomass and $\beta$-carotene density as well as the volumetric productivity of biomass $\left(\mathrm{g} \mathrm{dw} \mathrm{L}^{-1} \mathrm{~d}^{-1}\right)$ and $\beta$-carotene $(\mathrm{mg}$ 
$\mathrm{dw} \mathrm{L}^{-1} \mathrm{~d}^{-1}$ ) were calculated as a function of cultivation time:

$$
P_{\mathrm{av}, \mathrm{P}}=\frac{\rho_{\mathrm{P}}(t)-\rho_{\mathrm{P}}(0)}{t}
$$

where $t$ represent the cultivation time $(\mathrm{d})$ and $\rho_{\mathrm{P}}$ is the product density $\left(\mathrm{g} \mathrm{dw} \mathrm{L}^{-1}\right.$ or $\left.\mathrm{mg} \mathrm{dw} \mathrm{L}^{-1}\right)$. Furthermore, the time-averaged yields of biomass $Y_{X, E}$ and $\beta$-carotene on absorbed light energy $Y_{\beta, E}($ Fig. $7 \mathrm{c}-\mathrm{d})$ were calculated by dividing the time-averaged productivity $\left(\mathrm{mg} \mathrm{L}^{-1} \mathrm{~d}^{-1}\right)$ by the volumetric photon absorption rate of the evaluated time period (mol PAR photons $\mathrm{L}^{-1} \mathrm{~d}^{-1}$ ) according to Mulders et al. (2014a):

$$
Y_{\mathrm{P}, \mathrm{E}}=\frac{P_{\mathrm{av}, \mathrm{P}}}{\frac{E_{\mathrm{abs}} \cdot s_{\mathrm{R}}}{V_{\mathrm{R}}}}
$$

where $E_{\text {abs }}$ is the absorbed light (mol PAR photons $\left.\mathrm{m}^{-2} \mathrm{~d}^{-1}\right), s_{\mathrm{R}}$ the reactor surface $\left(0.024 \mathrm{~m}^{2}\right)$ and $V_{\mathrm{R}}$ the reactor volume $(1 \mathrm{~L})$.

\section{Results}

D. salina was cultivated in a flat-plate photobioreactor in batch mode under three different cultivation conditions (Table I). The adaptational abiotic stress response and their influence on the bioprocess performance represented by the biomass and $\beta$-carotene yield on absorbed light was analyzed under the presence of high light and nutrient stress.

\subsection{Cell growth}

The most important parameter for growth monitoring is the determination of the cell density. Absolute cell counting with a flow cytometer is a rapid and statistically reliable method to monitor the number of cells in a culture. The cell densities of the batch cultures were monitored until the early stationary growth phase was reached 
using true volumetric cell counting in samples diluted to approximately $1 \times 10^{6}$ cells $\mathrm{mL}^{-1}$. The forward scatter signal collected from $488 \mathrm{~nm}$ excitation was corrected for the non-algal background by applying a manual gate on the chlorophyll signal for all analyzed samples (Fig. 1a). Under control conditions, the algal cell population is the dominant type of event (95.7\%) detected compared to the background signal (4.3\%).

The time series for the biomass growth is shown in Fig. 1b. Comparing all three cultivation conditions, the high light culture (HL) reached the highest final cell density, $7.2 \times 10^{7}$ cells $\mathrm{mL}^{-1}$. The final cell densities reached in the stationary growth phase for the cultivations under low light (LL) as well as under high light and

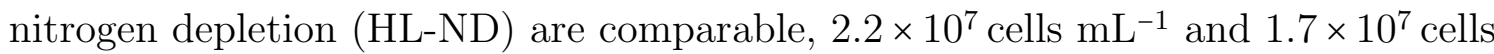
$\mathrm{mL}^{-1}$ (Fig. 1). All cultures had an initial lag phase of approximately one day until they entered the exponential growth phase. Depending on the cultivation conditions, the early stationary phase was reached at different time points. In the HL-ND culture the stationary growth phase was reached at day 7 , three days after the depletion of the extracellular nitrogen source (Fachet et al., 2014). The nitrogen-repleted cultures reached the stationary phase at day 8 and 10 for the LL and HL culture, respectively. The determination of the extracellular nitrogen density confirmed that only the growth of the HL-ND culture was nutrient-limited, whereas the growth of the LL and HL culture was only light- and never nutrient-limited (Fachet et al., 2014). The specific growth rates, final biomass densities and volumetric productivities for biomass and $\beta$-carotene for all three cultivation conditions are given in Table II.

\subsection{Formation of carotenoid-containing lipid globules led to increased granularity of} the cells

The accumulation of neutral lipids, which is a prerequisite for $\beta$-carotene accumulation, was detected by incubation with lipophilic fluorescent dyes. The suitability of 
the lipophilic dyes Nile Red and BODIPY 505/515 for staining of neutral lipids in D. salina was evaluated in microscopic images from stressed (HL-ND) and unstressed (LL) cells (Fig. 2). Staining of the cell suspension with both dyes led to comparable mean fluorescence emissions and time courses in the flow cytometer, whereby the Nile Red stained cell suspension showed slightly lower relative standard deviations (data not shown). The pattern of fluorescence emission of Nile Red allows to distinguish between polar membrane lipids, which emit red fluorescence upon excitation with blue light $(488 \mathrm{~nm})$, whereas the presence of neutral lipid globules lead to a fluorescence emission in the green and orange wavelength region (FL1 and FL2). The time courses for the green fluorescence of the neutral lipid globules was measured upon staining with Nile Red (Fig. 3a and b). The presence of high light conditions (HL, HL-ND) led to an instantaneous accumulation of neutral lipid globules, peaking in the maximum fluorescence after two days induction of the light stress (Fig. 3a and b). The fluorescence intensity reached almost comparable levels of 6.1 relative fluorescent units (RFU) under HL conditions and 5.1 RFU under HL-ND conditions. In the presence of nitrogen stress (HL-ND), two sub-population with different lipid fluorescence levels were identified, a large sub-population with high FSC signal (lipid-containing cells) and a sub-population with a significantly smaller size (released neutral lipid globules) (Fig. 3a and 8a). Under HL conditions the lipid content per cell declined gradually as a result of the adaptational stress response and the reduced light stress and returned to the initial level after 8 days. The neutral lipid content of the HL-ND culture was close to 5 RFU from day 2 to day 5 of cultivation (Fig. 3b). Ion chromatography of the cultivation medium revealed that the residual extracellular nitrate of the HL-ND culture was completely depleted at day 4 (for more details on time courses please see Fachet et al. (2014)). Two days after the depletion of the extracellular nitrate, a slight decrease in the intact cell fraction from $38 \%$ to $30 \%$ and a reduced fluorescein 
signal were detected by vitality staining (Fig. 5a). These factors indicate the cell death, which led to the release of the lipid-containing $\beta$-carotene globules resulting in a significantly reduced in lipid fluorescence at day 6 and 7 (Fig. 3b). This finding is in agreement with microscopic observations (Fig. 8a) and results from Davis et al. (2015). In their recent study, flow cytometry revealed the release of neutral lipid globules from the cells of the related organism Dunaliella virdis under high light and low salt stress.

During the environmental stress response, an increased intracellular granularity has been observed in microalgal cultures making this property a potentially useful marker for the physiological state of a cell (Hyka et al., 2013). The presence of abiotic stress often leads to the accumulation of storage molecules, such as starch, neutral lipid and $\beta$-carotene, resulting in a more complex internal structure and a larger proportion of scattered light. The variations in the cell granularity were analyzed using the geometric mean value of the side scatter signal in the flow cytometric analysis (Fig. 2a and b). Upon exposure to high light stress an initial increase of the cell granularity up to 3-fold compared to the basal level was detected until day 2 . The following decline of the granularity under HL conditions can be explained by a reduction in the stress level due to increasing $\beta$-carotene accumulation and cellular shading effects due to the biomass growth (Fig. 2a and b). The observed dynamics of neutral lipid fluorescence corresponded well to that of cell granularity (Fig. 4b and 9). This finding illustrates that the formation of neutral lipid globules results in more complex internal structure of the cell detected by a higher proportion of side-scattered light. 


\subsection{The presence of abiotic stress did not affect vitality of the intact cell population}

The cell vitality was determined by incubation of the cell suspension with the non-fluorescent compound FDA, which is converted to the green fluorescent compound fluorescein in the presence of active esterase enzymes in the mitochondrium of vital cells. The green fluorescence emission resulting from this reaction was monitored in a flow cytometer in the channel FL1 (Fig. 10a-c). The cell vitality in the culture is expressed as the ratio of vital cells to the total number of intact cells. Fig. 5a and b illustrate the effect of abiotic stress on the cell vitality of the culture. The vital cell fraction was calculated from the ratio of fluorescein-containing cells (FL1) to the total number of intact cells in the culture (determined by gating of the algal cell population in the FSC-FL3 plot as shown in Fig. 1a). The flow cytometric vitality assay showed that the vitality under all three selected conditions is always above $90 \%$. This clearly indicates that even under abiotic stress conditions (HL and HL-ND) no significant dead cell sub-population with FSC-FL3 characteristics of intact cells can observed. However, upon exposure to HL and the HL-ND stress a strong cell breakage and lipid particle release was detected by a rising fraction of particles with smaller size in the FSC channel (Fig. 8a). Only for the last data point of the HL-ND cultivation (day 7), two separate sub-populations with different vitalities were detected, where approximately $50 \%$ of the culture emitted a lower fluorescent signal (67 RFU) than the other half of the culture (161 RFU) (Fig. 5a). This observation may have several reasons. On the one hand, the persistent light and nutritional stress could lead to a reduced esterase enzyme activity reflected by the lower fluorescein conversion and signal intensity. On the other hand, the cell death-induced permeabilization of the mitochondrial membrane or the cell membrane could impair the dye retention leading to an outflow of converted fluorescein from the cells. The transient phase of reduced enzymatic activity and increased membrane permeability occurring during cell death 
was detected by the vitality staining only for last data point under HL-ND conditions, where the stress was very persistent and cell death affected a large percentage of the culture (Fig. 5a). After 8 days of cultivation, a further analysis of cellular properties was no longer possible, since the HL-ND conditions led to a complete destruction of the population due to cell death. Although, a vital cell fraction above $90 \%$ could be detected at all time points and under all cultivation conditions, the vitality staining can provide important information for bioprocess monitoring. The results revealed that cell breakage upon abiotic stress occurs quickly and no significant non-vital but intact cell population can be detected, if it only affects a small fraction of the cell population. However, if a large fraction of cells is affected by cell death, a significant loss in fluorescein signal intensity (as observed for day 7 of the HL-ND culture) seems to be a critical marker for the determination of optimal harvesting time points.

\subsection{Accumulation of $\beta$-carotene correlated with neutral lipid dynamics}

The photon flux density at the reactor surface $E_{0}$ was constant during all cultivations but the average photon flux density $\bar{E}$ during the cultivations was subject to fluctuations depending on the pigment composition and the biomass density in the reactor. The abiotic stress-induced pigment adaption in D. salina was measured using HPLC analysis.

Fig. 6a illustrates the time course of the pigments $\beta$-carotene, chlorophyll $a$ and $b$ as a function of cultivation time. The initial chlorophyll fractions at the beginning of the cultivations deviate from each other, because of the different final cell densities in the inoculum. The stock cultures used for the LL and HL-ND batch were in late exponential phase, whereas the stock culture for the HL batch was in mid exponential phase. Since the stock culture photoacclimate to the light conditions in the shaking incubator, the HL stock culture had a reduced chlorophyll content compared to 
the LL and HL-ND inoculum at the time point $\mathrm{t}=0$. Under all three cultivation conditions (LL, HL and HL-ND), the amount of absorbed light energy in the initial cultivation phase is higher than the energy required for growth. This imbalance led to a reduction in the chlorophyll pigment fraction due to photoacclimation processes. During high light stress (HL and HL-ND) the rate of chlorophyll $b$ degradation is higher compared to that of chlorophyll $a$ leading to a higher chlorophyll $a / b$ ratio (Fig. 6b). Under low light conditions, the chlorophyll $a / b$ ratio remains low, which is in agreement with previous studies from Webb and Melis (1995). The presence of high light stress induced the accumulation of $\beta$-carotene in the HL and HL-ND culture after 2 days of cultivation. Under HL conditions, the $\beta$-carotene content was maximal after 2 days and reached a fraction of $24 \mathrm{mg} \mathrm{g}^{-1} \mathrm{dw}$ leading to a maximal $\beta$-carotene/chlorophyll ratio of 3.1 (Fig. 6c). With increasing $\beta$-carotene content, the cells were able to overcome the presence of light stress, detected by an increasing photochemical quantum yield (Fig. 6d). During the initial growth phase under light stress, the maximal photochemical quantum yield of photosystem (PS) II dropped from 0.67 to 0.21 within $24 \mathrm{~h}$, which reflect that D. salina is not able to adapt well to the light stress. This effect but to a lesser extent has been observed by $\mathrm{Gu}$ et al. (2014), who measured a drop from 0.7 to 0.6 in the maximal PSII quantum yield measured a decrease after $48 \mathrm{~h}$ after induction with a less severe light stress of $1000 \mu \mathrm{mol}$ photons $\mathrm{m}^{-2} \mathrm{~s}^{-1}$. During saturating light conditions, the photon absorption rate of the antenna is significantly higher than the linear electron transfer rate resulting in a decrease of the antenna size and large fraction of light needing to be dissipated by non-photochemical quenching (Ihnken et al., 2011; Perrine et al., 2012). After the light-induced $\beta$-carotene accumulation, the cell density increased and the PSII quantum yield achieved its initial level 8 days after induction of light stress. 
After depletion of the residual nitrate in the cultivation medium of the HL-ND culture, the $\beta$-carotene content of the biomass increased continuously to a final level of $48 \mathrm{mg} \mathrm{g}^{-1} \mathrm{dw}$ corresponding to a $\beta$-carotene/chlorophyll ratio of 8.6 (Fig. 6c). Although, the $\beta$-carotene containing lipid globules were released from the cell as observed in Fig. 8a, the $\beta$-carotene was still detectable in the HPLC analysis, because the released globules were collected together with the biomass in the pellet. The $\beta$-carotene fractions in the biomass under HL conditions are comparable to published values (24 $\mathrm{g} \mathrm{g}^{-1} \mathrm{dw}$ compared to $30 \mathrm{mg} \mathrm{g}^{-1} \mathrm{dw}$ ), whereas the values for HL-ND cultivation are lower in this study (48 $\mathrm{g} \mathrm{g}^{-1} \mathrm{dw}$ compared to $70 \mathrm{mg} \mathrm{g}^{-1} \mathrm{dw}$ ) (Lamers et al., 2010).

\subsection{Biotechnological parameters}

The most productive cultivation conditions in terms of biomass yield on absorbed light energy was obtained in the LL culture, because the light-limiting regime led to the most efficient light use of all three selected conditions (Fig. 7a). The highest volumetric biomass productivity was achieved under HL conditions with $0.46 \mathrm{~g} \mathrm{dw} \mathrm{\textrm {L } ^ { - 1 }}$ $\mathrm{d}^{-1}$, because this cultivation condition led to the highest final cell densities (Table II). The highest $\beta$-carotene productivity was observed in the HL-ND culture with 11.4 mg $\beta$-carotene $\mathrm{L}^{-1} \mathrm{~d}^{-1}$ (Table II). However, due to presence of the high incident light the $\beta$-carotene yield on absorbed light $Y_{\beta, E}$ under HL-ND conditions was slightly lower compared to LL conditions (3.1 mg mol${ }^{-1}$ photons compared to $3.9 \mathrm{mg} \mathrm{mol}^{-1}$ photons). This result suggests that under LL conditions, where the $\beta$-carotene fraction in the biomass is significantly lower compared to HL-ND conditions, $\beta$-carotene only acts as primary pigment, whereas it serves as a secondary pigment under HL-ND conditions. The yield of secondary carotenoids on absorbed photons is an important process parameter in order to estimate the performance and to optimize large scale 
systems, but has only rarely been addressed in previous studies. Recently, Mulders et al. (2014a) published for the first time a secondary carotenoid yield on absorbed light of $2.75 \mathrm{mg} \mathrm{mol}^{-1}$ photons for Chlorella zofingiensis cultivated under nitrogendepleted conditions. The values obtained in this study are higher, likely due to of the higher light stress $\left(1950 \mu \mathrm{mol}\right.$ photons $\mathrm{m}^{-2} \mathrm{~s}^{-1}$ compared to $245 \mu \mathrm{mol}$ photons $\mathrm{m}^{-2} \mathrm{~s}^{-1}$ incident light) and the lower biomass density on dry weight basis in our study (1.5 g $\mathrm{dw} \mathrm{L}^{-1}$ compared to 2.5, 3.4 and $\left.4.1 \mathrm{~g} \mathrm{dw} \mathrm{L}^{-1}\right)$. In addition, the high neutral lipid yield on light of $C$. zofingiensis with $320 \mathrm{mg}$ TAG mol${ }^{-1}$ photons might explain the lower secondary carotenoid yield on light, because the storage of excess energy in form of lipids might be preferable used in this organisms. Additionally, the detailed studies performed by Lamers et al. (2010) and Lamers et al. (2012) cultivating D. salina under high light conditions $\left(1400 \mu \mathrm{mol}\right.$ photons $\mathrm{m}^{-2} \mathrm{~s}^{-1}$ incident light $)$ as well as under low light (200 $\mu \mathrm{mol}$ photons $\mathrm{m}^{-2} \mathrm{~s}^{-1}$ incident light) and nutrient-limited conditions in a turbidostat achieved higher volumetric $\beta$-carotene productivities $\left(37 \mathrm{mg} \mathrm{L}^{-1} \mathrm{~d}^{-1}\right.$ under HL conditions, $18.5 \mathrm{mg} \mathrm{\textrm {L } ^ { - 1 }} \mathrm{d}^{-1}$ under LL conditions) and $\beta$-carotene yield on light (4.6 mg mol${ }^{-1}$ under HL conditions, $16.2 \mathrm{mg} \mathrm{mol}^{-1}$ under LL conditions) compared to this study using batch operation mode. This outcome clearly indicates that innovative process design approaches have a large potential to optimize the performance of biotechnological processes.

\section{Conclusion}

In this work, a broad spectrum of cellular properties related to the abiotic stress response during $\beta$-carotene accumulation in D. salina was characterized by flow cytometry. This experimental setup enables the determination of critical process parameters and can therefore provide information about optimal harvesting time points. For this study, the highest productivity and the time-optimal yield on 
absorbed light for $\beta$-carotene has been achieved at day 5 of the HL-ND culture. The flow cytometric analysis supported this finding by detecting a high neutral lipid fluorescence and cell vitality in the population at this time point. In addition, the presence of high light stress induced a pronounced cell disruption in the whole population. However, the vitality of the intact cells was always above $90 \%$ for all three investigated conditions. The staining with FDA and Nile Red demonstrated a population heterogeneity with two sub-populations in the vitality and the lipid fluorescence for the nitrogen-stressed culture. The $\beta$-carotene yield on absorbed light is with $3.1 \mathrm{mg} \mathrm{mol}^{-1}$ the highest reported value for secondary carotenoids in literature. In combination with a dynamic kinetic model for the growth of D. salina, the results of this work support the systematic analysis and robust design of efficient bioproduction processes under biological uncertainties due to the cellular stress response.

\section{Acknowledgements}

This research work was partly supported by the Center for Dynamic Systems (CDS) funded by the Federal State Saxony-Anhalt (Germany). The authors gratefully thank Markus Ikert and Saskia Nickel for their technical support in pigment extraction and detection as well as Markus Janasch for support of the flow cytometric measurements and the optimization of the staining conditions. The authors declare no conflict of interest.

\section{References}

Ben-Amotz, A., Katz, A., Avron, M., 1982. Accumulation of $\beta$-carotene in halotolerant algae: Purification and characterization of $\beta$-carotene-rich globules from Dunaliella bardawil (Chlorophyceae). J Phycol 18, 529-537. 
Biller, P., Ross, A., 2014. Pyrolysis GCMS as a novel analysis technique to determine the biochemical composition of microalgae. Algal Res 6, Part A, 91-97.

Bougaran, G., Rouxel, C., Dubois, N., Kaas, R., Grouas, S., Lukomska, E., Le Coz, J.R., Cadoret, J.P., 2012. Enhancement of neutral lipid productivity in the microalga Isochrysis affinis galbana (T-Iso) by a mutation-selection procedure. Biotechnol Bioeng 109, 2737-2745.

Brennan, L., Blanco Fernández, A., Mostaert, A., Owende, P., 2012. Enhancement of BODIPY 505/515 lipid fluorescence method for applications in biofuel-directed microalgae production. J Microbiol Meth 90, 137-143.

Chen, W., Zhang, C., Song, L., Sommerfeld, M., Hu, Q., 2009. A high throughput Nile red method for quantitative measurement of neutral lipids in microalgae. J Microbiol Meth 77, 41-47.

Davis, R.W., Carvalho, B.J., Jones, H.D.T., Singh, S., 2015. The role of photo-osmotic adaptation in semi-continuous culture and lipid particle release from Dunaliella viridis. J Appl Phycol 27, 109-123.

Fachet, M., Flassig, R., Rihko-Struckmann, L., Sundmacher, K., 2014. A dynamic growth model of Dunaliella salina: Parameter identification and profile likelihood analysis. Bioresour Technol 173C.

Govender, T., Ramanna, L., Rawat, I., Bux, F., 2012. BODIPY staining, an alternative to the Nile red fluorescence method for the evaluation of intracellular lipids in microalgae. Bioresour Technol 114, 507-511.

Gu, W., Li, H., Zhao, P., Yu, R., Pan, G., Gao, S., Xie, X., Huang, A., He, L., Wang, G., 2014. Quantitative proteomic analysis of thylakoid from two microalgae 
(Haematococcus pluvialis and Dunaliella salina) reveals two different high lightresponsive strategies. Sci Rep 4.

Havlik, I., Lindner, P., Scheper, T., Reardon, K., 2013. On-line monitoring of large cultivations of microalgae and cyanobacteria. Trends Biotechnol 31, 406-414.

Hejazi, M., Holwerda, E., Wijffels, R., 2004. Milking microalga Dunaliella salina for $\beta$-carotene production in two-phase bioreactors. Biotechnol Bioeng 85, 475-81.

Hyka, P., Lickova, S., Přibyl, P., Melzoch, K., Kovar, K., 2013. Flow cytometry for the development of biotechnological processes with microalgae. Biotechnol Adv 31, $2-16$.

Ihnken, S., Kromkamp, J., Beardall, J., 2011. Photoacclimation in Dunaliella tertiolecta reveals a unique NPQ pattern upon exposure to irradiance. Photosynth Res $110,123-37$.

Jiménez, C., Capasso, J., Edelstein, C., Rivard, C., Lucia, S., Breusegem, S., Berl, T., Segovia, M., 2009. Different ways to die: cell death modes of the unicellular chlorophyte Dunaliella viridis exposed to various environmental stresses are mediated by the caspase-like activity DEVDase. J Exp Bot 60, 815-28.

Koller, M., Muhr, A., Braunegg, G., 2014. Microalgae as versatile cellular factories for valued products. Algal Res 6, Part A, 52-63.

Lamers, P., van de Laak, C., Kaasenbrood, P., Lorier, J., Janssen, M., De Vos, R., Bino, R., Wijffels, R., 2010. Carotenoid and fatty acid metabolism in light-stressed Dunaliella salina. Biotechnol Bioeng 106, 638-648. 
Lamers, P.P., Janssen, M., De Vos, R.C.H., Bino, R.J., Wijffels, R.H., 2012. Carotenoid and fatty acid metabolism in nitrogen-starved Dunaliella salina, a unicellular green microalga. Journal of Biotechnology .

Mendoza, H., Martel, A., del Rio, M., Reina, G., 1999. Oleic acid is the main fatty acid related with carotenogenesis in Dunaliella salina. J Appl Phycol 11, 15-19.

Mendoza Guzmán, H., de la Jara Valido, A., Freijanes Presmanes, K., Carmona Duarte, L., 2012. Quick estimation of intraspecific variation of fatty acid composition in Dunaliella salina using flow cytometry and Nile red. J Appl Phycol 24, 1237-1243.

Mulders, K., Janssen, J., Martens, D., Wijffels, R., Lamers, P., 2014a. Effect of biomass concentration on secondary carotenoids and triacylglycerol (TAG) accumulation in nitrogen-depleted Chlorella zofingiensis. Algal Res 6, Part A, 8-16.

Mulders, K., Lamers, P., Martens, D., Wijffels, R., 2014b. Phototrophic pigment production with microalgae: biological constraints and opportunities. J Phycol 50, $229-242$.

Olson, R., Vaulot, D., Chisholm, S., 1985. Marine phytoplankton distributions measured using shipboard flow cytometry. Deep Sea Res 32, 1273-1280.

Pérez-Clemente, R., Vives, V., Zandalinas, S., López-Climent, M., Muñoz, V., GómezCadenas, A., 2013. Biotechnological approaches to study plant responses to stress. Biomed Res Int 2013, 10.

Perrine, Z., Negi, S., Sayre, R., 2012. Optimization of photosynthetic light energy utilization by microalgae. Algal Res 1, 134-142. 
Polle, J., Niyogi, K., Melis, A., 2001. Absence of lutein, violaxanthin and neoxanthin affects the functional chlorophyll antenna size of photosystem II but not that of photosystem I in the green alga Chlamydomonas reinhardtii. Plant Cell Physiol 42, $482-91$.

Rabbani, S., Beyer, P., Von Lintig, J., Hugueney, P., Kleinig, H., 1998. Induced $\beta$-carotene synthesis driven by triacylglycerol deposition in the unicellular alga Dunaliella bardawil. Plant Physiol 116, 1239-1248.

da Silva, T., Santos, C., Reis, A., 2009. Multi-parameter flow cytometry as a tool to monitor heterotrophic microalgal batch fermentations for oil production towards biodiesel. Biotechnol Bioproc E 14, 330-337.

Wagner, H., Liu, Z., Langner, U., Stehfest, K., Wilhelm, C., 2010. The use of FTIR spectroscopy to assess quantitative changes in the biochemical composition of microalgae. J Biophotonics 3, 557-66.

Webb, M., Melis, A., 1995. Chloroplast response in Dunaliella salina to irradiance stress - effect on thylakoid membrane-protein assembly and function. Plant Physiol $107,885-893$.

de Winter, L., Klok, A., Cuaresma Franco, M., Barbosa, M., Wijffels, R., 2013. The synchronized cell cycle of Neochloris oleoabundans and its influence on biomass composition under constant light conditions. Algal Res 2, 313-320.

Xie, B., Stessman, D., Hart, J., Dong, H., Wang, Y., Wright, D., Nikolau, B., Spalding, M., Halverson, L., 2014. High-throughput fluorescence-activated cell sorting for lipid hyperaccumulating Chlamydomonas reinhardtii mutants. Plant Biotechnol J $12,872-882$. 
Table I: Overview of experimental conditions (Fachet et al., 2014)

\begin{tabular}{llcc}
\hline Abbreviation & Description & $\begin{array}{c}\text { Photon flux density } \\
\left(\mu \mathrm{mol} \mathrm{m}{ }^{-2} \mathrm{~s}^{-1}\right)\end{array}$ & $\begin{array}{c}\text { Extracellular nitrogen } \\
\text { density }(\mathrm{g} / \mathrm{L})\end{array}$ \\
\hline LL & Low light & 175 & 0.5 \\
HL & High light & 1950 & 0.5 \\
HL-ND & High light and & 1950 & 0.017 \\
& nitrogen depletion & & \\
\hline
\end{tabular}


Table II: Comparison of final biomass density on dry weight basis and volumetric productivities

\begin{tabular}{lccc}
\hline Parameter & $\begin{array}{c}\text { Low light } \\
(\mathrm{LL})\end{array}$ & $\begin{array}{c}\text { High light } \\
(\mathrm{HL})\end{array}$ & $\begin{array}{c}\text { High light and } \\
\text { nitrogen depletion } \\
\text { (HL-ND) }\end{array}$ \\
\hline $\begin{array}{l}\text { Specific growth rate } \\
\left(\mathrm{d}^{-1}\right)\end{array}$ & 0.49 & 0.64 & 0.58 \\
$\begin{array}{l}\text { Time-averaged volumetric biomass } \\
\left.\text { productivity (g dw L } \mathrm{d}^{-1}\right)\end{array}$ & 0.12 & 0.46 & 0.19 \\
$\begin{array}{l}\text { Time-averaged volumetric } \beta \text {-carotene } \\
\left.\text { productivity (mg L } \mathrm{m}^{-1} \mathrm{~d}^{-1}\right)\end{array}$ & 0.35 & 1.82 & 11.4 \\
\hline
\end{tabular}


Figure 1: Effect of abiotic stress type on the cell growth of D. salina. a) Scatter plot representing the position of the algal cell population based on cell size (FSC) and chlorophyll fluorescence (FL3) for the inoculum culture of the low light cultivation. b) Cell density growth curves for the three investigated cultivation conditions; LL low light, HL - high light, HL-ND - high light and nitrogen depletion. The symbols represent the mean values and the error bars correspond to the deviation from the average value of duplicate measurements.

Figure 2: Epifluorescence image of D. salina stained with a) Nile Red and b) BODIPY 505/515.

Figure 3: Effect of abiotic stress type on the neutral lipid fluorescence. a) Histograms for samples with a low (light red, HL-ND) or a high neutral lipid fluorescence (red, HL-ND). b) Time series of the neutral lipid fluorescence. The asterisks (*) in b) correspond to the data points in the time series presented in histograms. The geometric mean values of the fluorescence signal intensities were determined in Nile Red $\left(0.5 \mu \mathrm{g} \mathrm{mL}^{-1}\right)$ stained diluted cell suspensions $\left(1 \times 10^{6}\right.$ cells $\left.\mathrm{mL}^{-1}\right)$. The symbols represent the mean values and the error bars correspond to the deviation from the average value of duplicate measurements.

Figure 4: Effect of abiotic stress type on the side scattered light (SSC) of the cells. a) Histograms for samples with a low (light red, HL-ND) or a high intracellular granularity (red, HL-ND). b) Time series of the intracellular granularity. The asterisks $\left(^{*}\right)$ in and b) correspond to the data points in the time series presented in histograms. The symbols represent the mean values and the error bars correspond to the deviation from the average value of duplicate measurements. 
532

536

Figure 5: Effect of abiotic stress type on the cell vitality of the population. a) Histograms for samples with a high (light red, HL-ND) or a low cell vitality (red, HL-ND). b) Time series of the cell vitality in the culture. The asterisks $(*)$ in b) correspond to the data points in the time series presented in histograms. The geometric mean values of the fluorescence signal intensities were determined in FDA $\left(40 \mu \mathrm{g} \mathrm{mL}{ }^{-1}\right)$ stained diluted cell suspensions $\left(1 \times 10^{6}\right.$ cells $\left.\mathrm{mL}^{-1}\right)$. The symbols represent the mean values and the error bars correspond to the deviation from the average value of duplicate measurements.

Figure 6: Effect of abiotic stress type on the a) pigment composition, b) chl $a / b$ ratio, c) $\beta$-carotene/chl ratio and d) the photosynthetic performance represented by the maximum photochemical quantum yield of PSII $\left(\Phi_{\mathrm{II}}\right)$.

Figure 7: Effect of abiotic stress type on a) the biomass density on dry weight basis, b) the $\beta$-carotene density, c) the time-averaged biomass yield on absorbed light $Y_{\mathrm{X}, \mathrm{E}}$ and d) the time-averaged $\beta$-carotene yield on absorbed light $Y_{\beta, \mathrm{E}}$. 


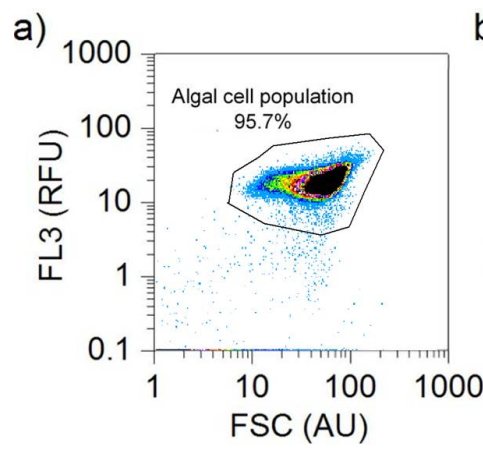

b)

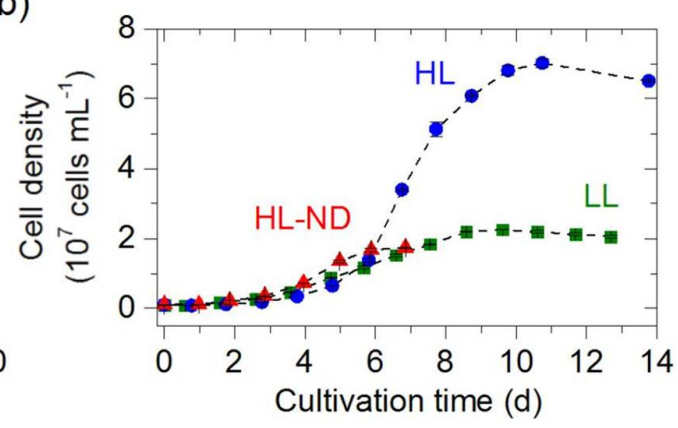

Figure 1 
a)

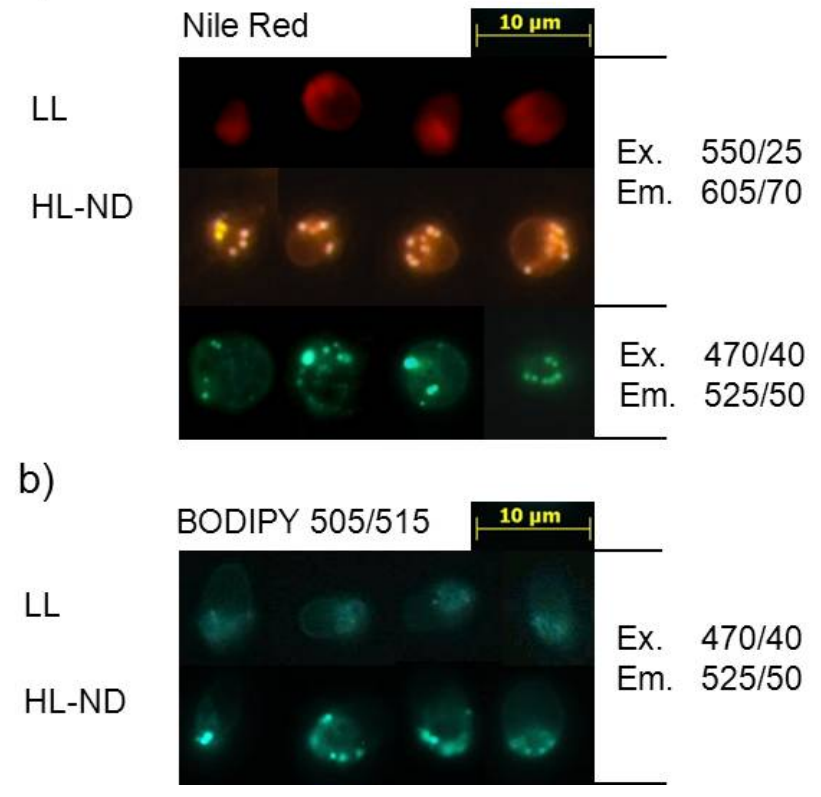

Figure 2 

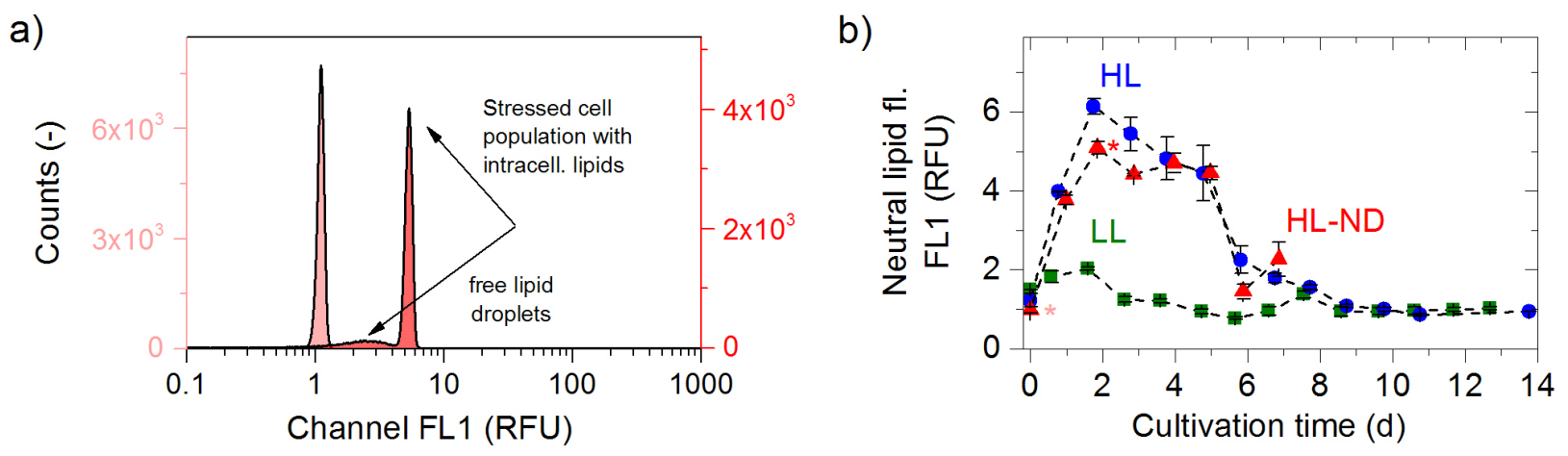

Figure 3 

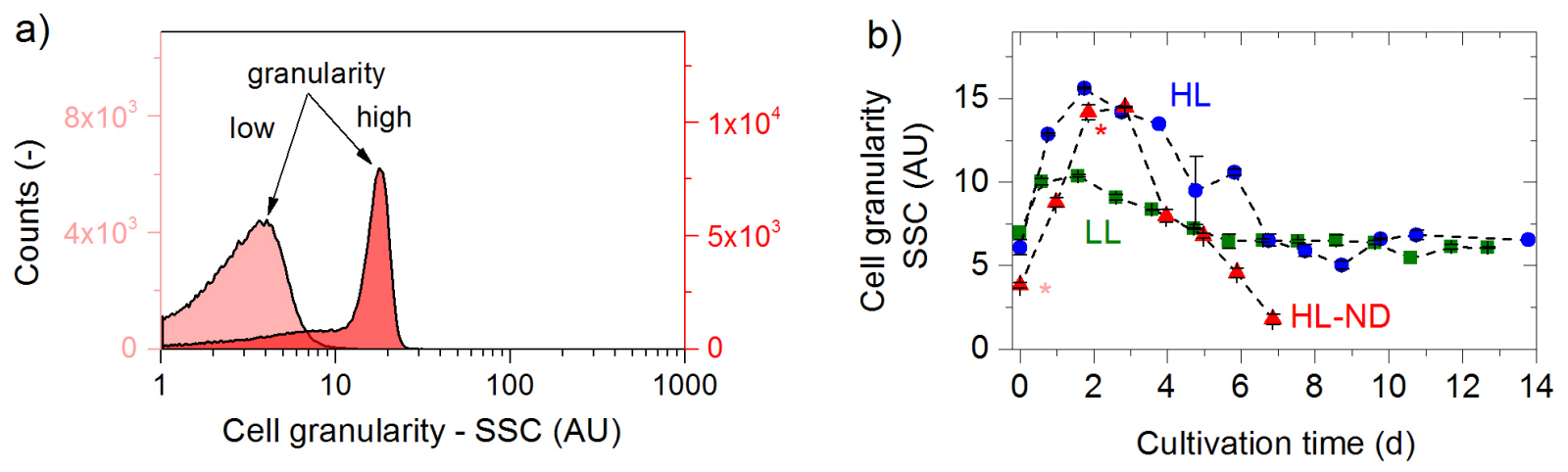

Figure 4 

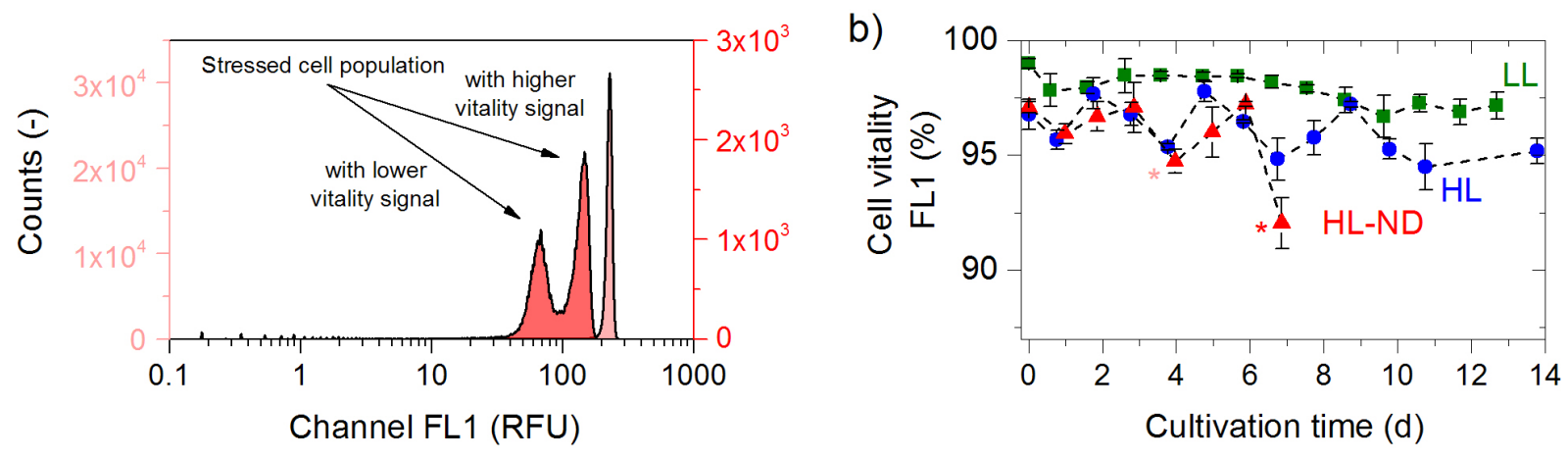

Figure 5 

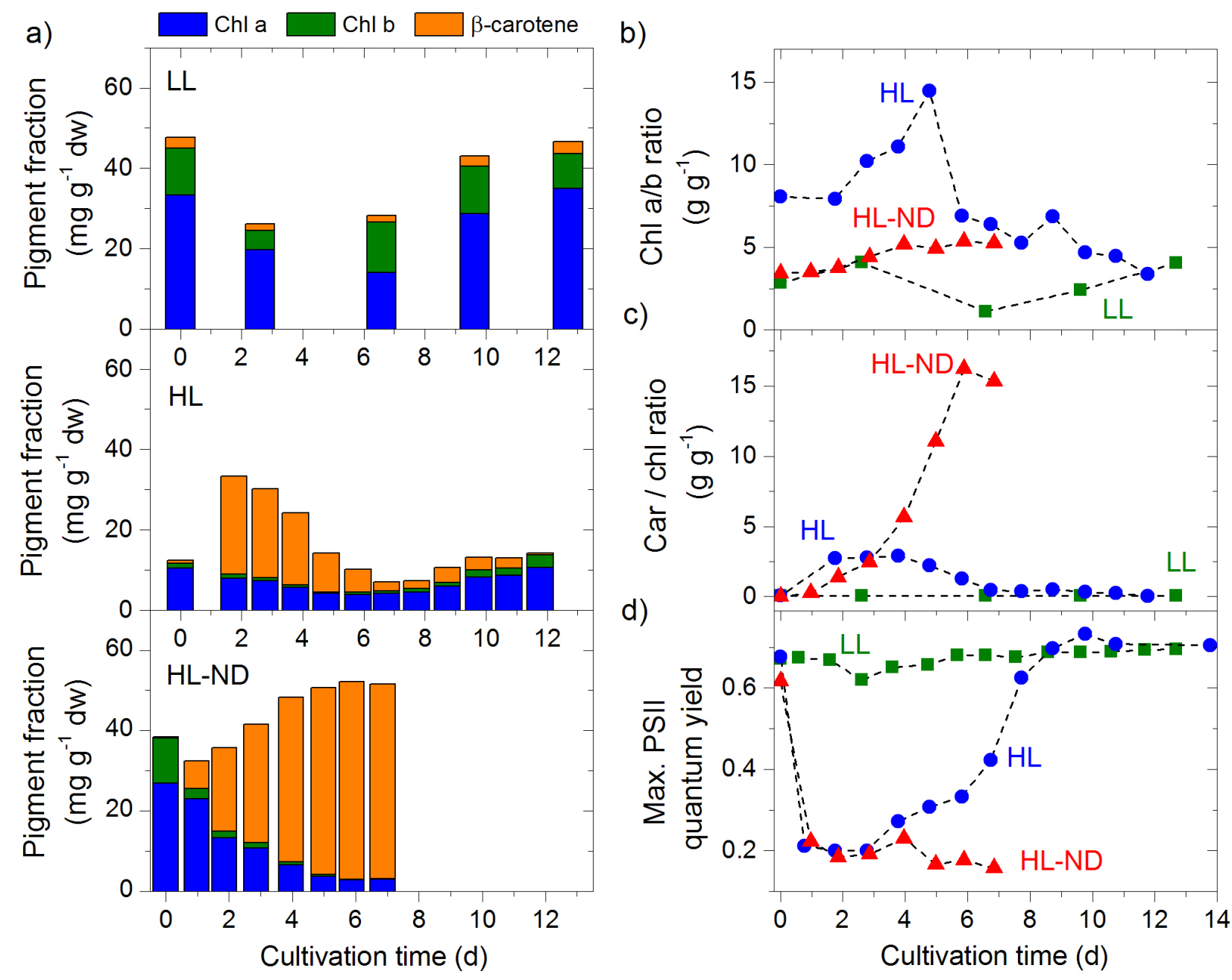

Figure 6 
a)

b)

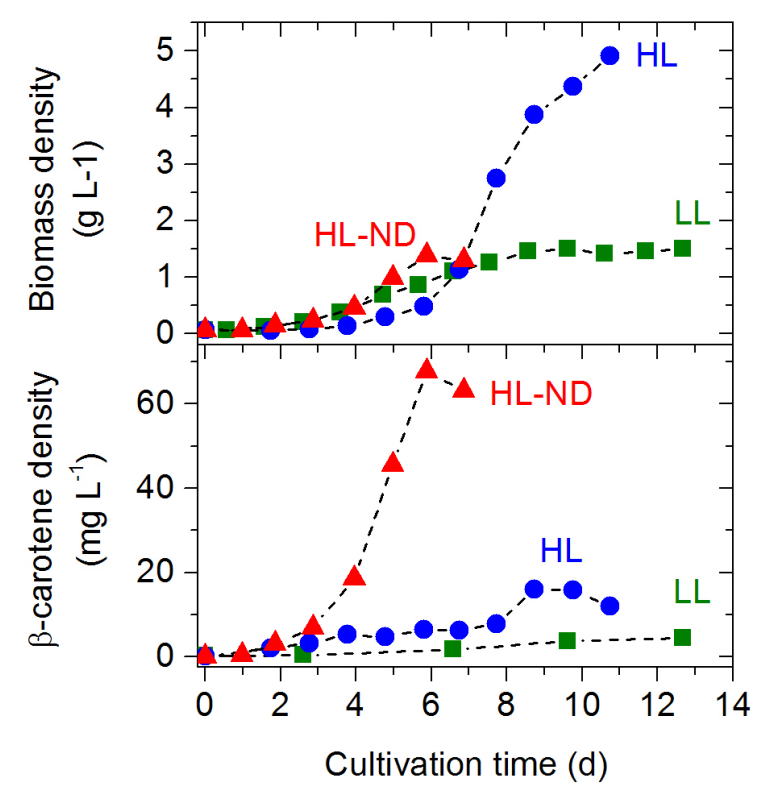

c)

d)
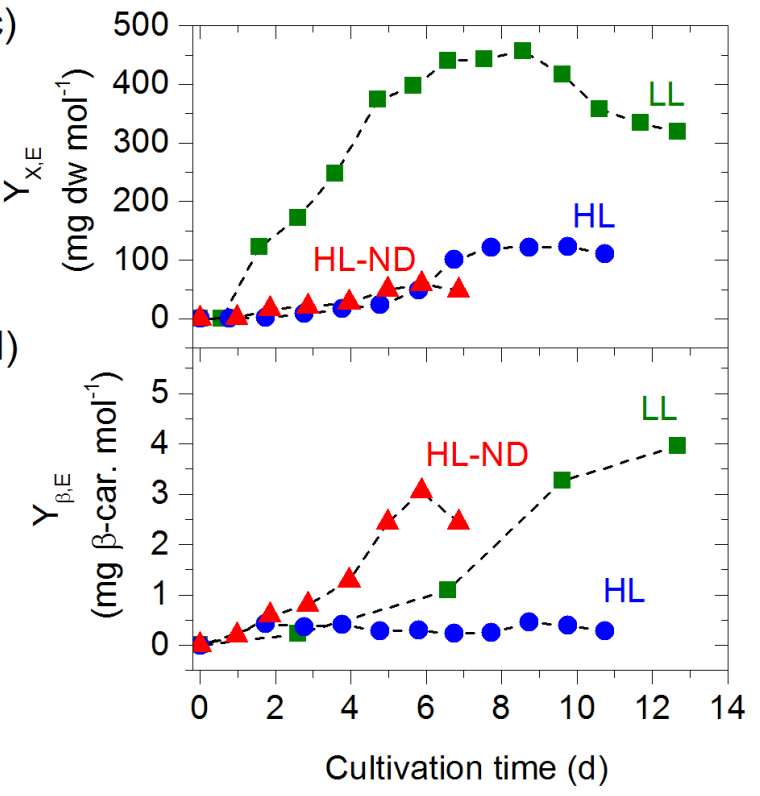

Figure 7 